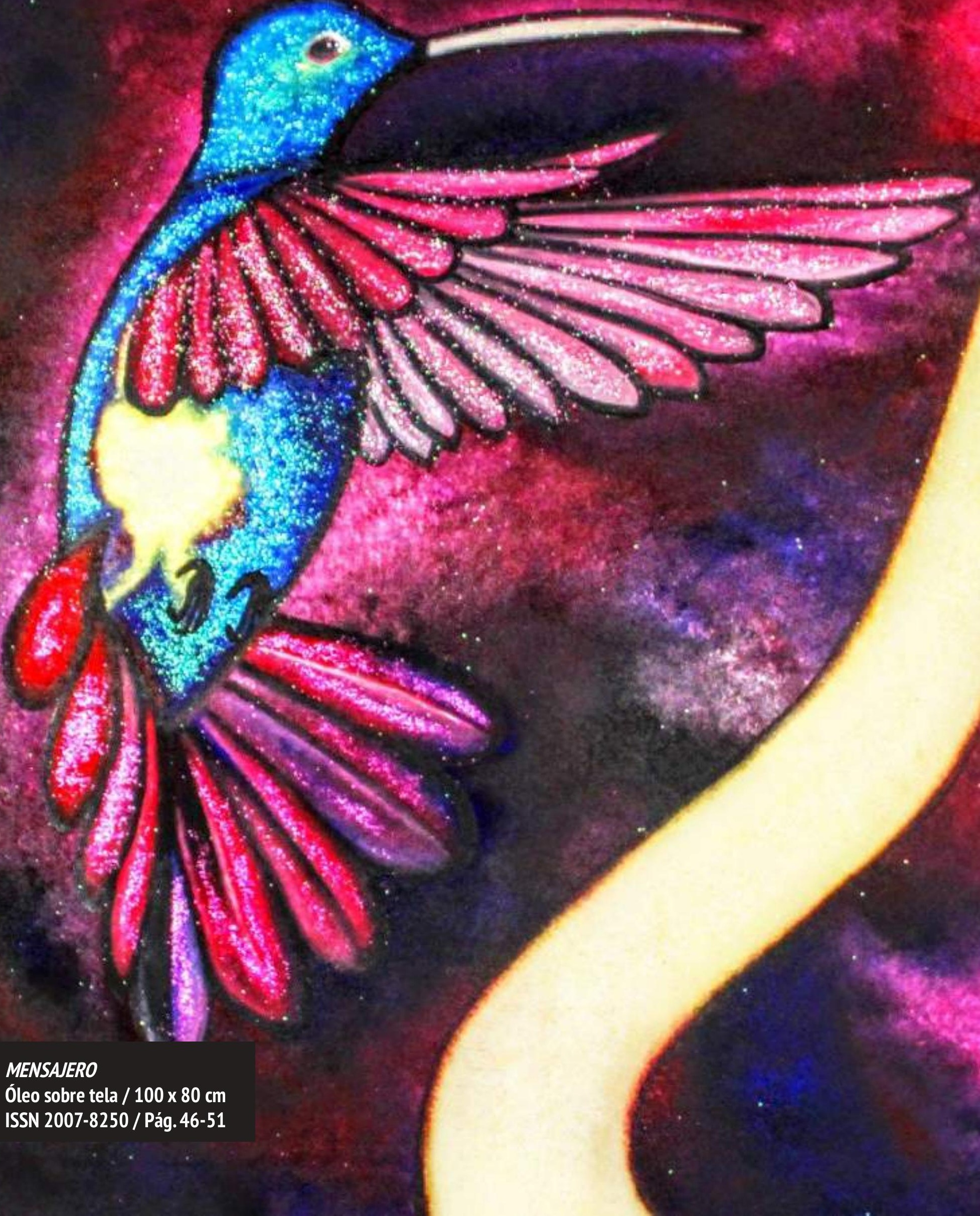




\section{NUESTRA MATERIA DE ENSEÑANZA A TRAVÉS DE APRENDIZAJE SIGNIFICATIVO}

\section{Oscar Roberto Villalobos Saldaña}

No. 9 - Septiembre 1993

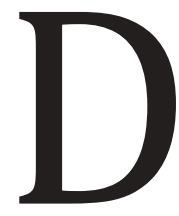

esde sus orígenes, el hombre ha sentido la necesidad de enseñar y transmitir sus conocimientos, experiencias y descubrimientos a las generaciones siguientes. Por esta razón, podemos considerar que la enseñanza como actividad humana ha ido dándose de una u otra manera con los recursos propios de cada sociedad, en su momento, manejándose con frecuencia a base de verdades acabadas 0 estáticas. 
in embargo, el hombre que vive en la era de los vuelos espaciales, de la computación más sofisticada y de los grandes retos de las sociedades modernas, no puede continuar aprendiendo a través de verdades que le son impuestas, donde el análisis y la reflexión revistan poca importancia. El hombre de nuestros días vive en ambientes de cambio continuo.

Ciertos supuestos de la Física que se enseña hoy a los estudiantes, habrán sido superados en algunas décadas; ni hablar de otras áreas tales como la Psicología o la Sociología, cuyas verdades se hallan vulnerables a constantes procesos de transformación, determinados en gran parte por la cultura y costumbres de los diferentes pueblos en la relación a su tiempo.

En la actualidad, los educadores modernos nos enfrentamos ante la urgencia de saber orientar nuestras materias de enseñanza en base a la llamada Facilitación del Aprendizaje.

Sólo habremos tenido éxito en nuestra tarea formadora en la medida que nuestros alumnos aprendan a evolucionar y comprendan que la finalidad del conocimiento es la de transformar al hombre y encauzarlo hacia nuevas y mejores pautas de conducta que le permitan vivir de mejor manera en base a la valoración y estima humana que tienda al bienestar propio y al de los demás.

Uno de los mayores retos de la educación actual es el de enseñar al individuo a que piense y reflexione acerca del por qué y para qué de los diferentes procesos de aprendizaje

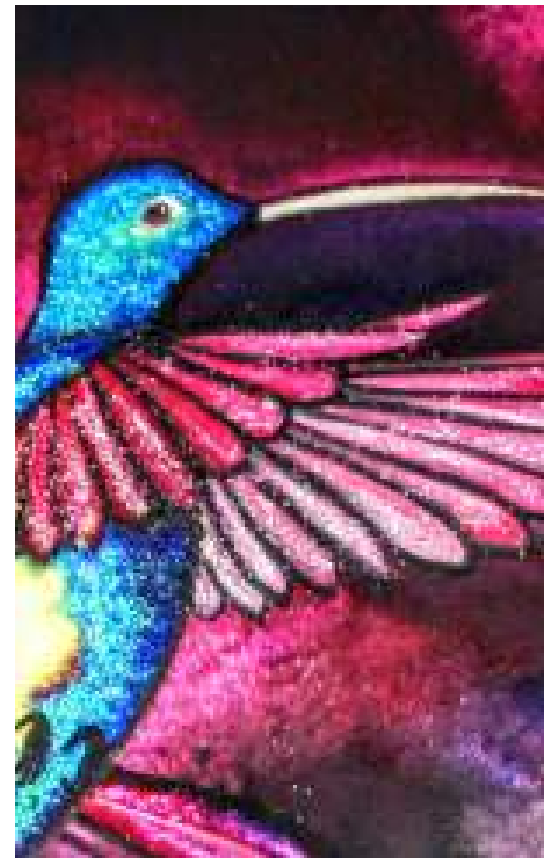

en los que participa; propiciando en él una formación crítica y autocrítica, de búsqueda constante, donde no hay cabida a verdades acabadas ni a conocimientos estáticos.

Liberar la curiosidad, permitir que nuestros alumnos evolucionen según sus propios intereses, alentar su deseo de indagación, abrir todo a la pregunta y a la explicación, reconocer que el conocimiento trae como consecuencia nuevas búsquedas, son aspectos que revisten gran importancia. Es aquí donde surge aquel apotegma de educar para la vida, donde realmente deseamos conformar personalidades más seguras, más crea-

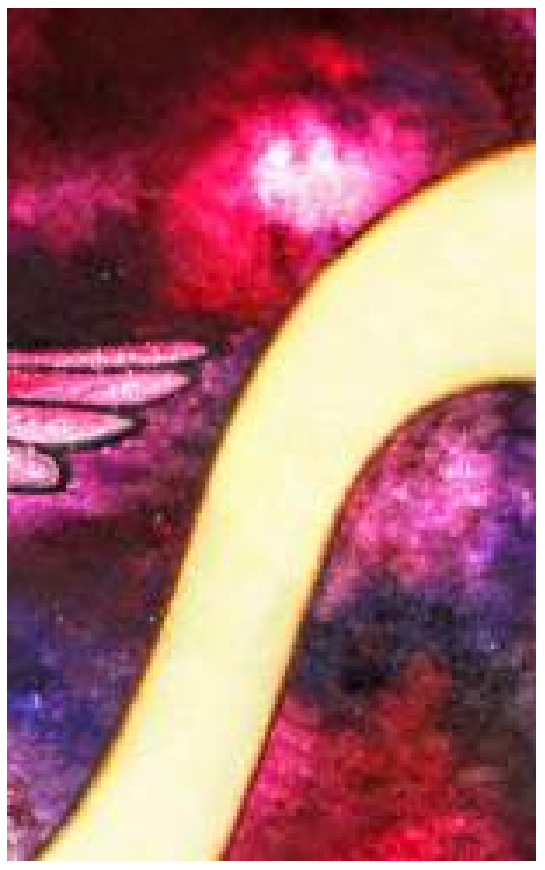

tivas y con mayor equilibrio entre lo que saben y lo que les falta aún por saber, para obtener una mejor concepción de los hechos y fenómenos de la vida.

La facilitación del aprendizaje se logra mediante métodos y técnicas donde el que aprende se vuelve altamente participativo, se le enseña a formular cuestionamientos útiles, flexibles y de gran apertura hacia la investigación sobre diversas problemáticas, que como maestros conocemos con el nombre de objetivos de aprendizaje. Esto presupone la estimulación de un proceso educativo más dinámico y vivencial. 
La actitud de ponerse en el lugar del otro, de ver el mundo desde el punto de vista del estudiante, es casi inaudita en la escuela tradicional

A este respecto, el psicoterapeuta Carl R. Rogers, en su libro Freedom and Creativity in Education, establece lo siguiente:

La incentivación del aprendizaje no depende de las cualidades didácticas del líder, de su conocimiento erudito de la materia, de la planificación del currículum, del uso de los materiales, de la aplicación de la enseñanza programada, de sus conferencias y presentaciones, ni de la abundancia de libros; aunque todos estos elementos podrían constituir recursos útiles en algunas ocasiones, lo verdaderamente importante es lograr un aprendizaje significativo, aunque esto depende de ciertas actitudes que se re- velan en la relación interpersonal entre el maestro y el educando.

Diversos psicólogos y pedagógos contemporáneos coinciden en señalar la importancia de una relación comprensiva y empática por parte del maestro que, con la adecuada utilización de una metodología que invite a la participación activa del alumno, dé por resultado aprendizajes significativos.

Cuando el encargado de enseñar y educar tiene la capacidad de comprender las relaciones del que aprende, cuando se tiene una percepción sensible de cómo se le presenta el proceso de aprendizaje a éste último, entonces puede hablarse ya de la facilitación psico-pedagógica de un aprendizaje significativo.

Este tipo de comprensión es totalmente diferente del que responde al modelo de: Comprende tus deficiencias. Por su parte, cuando existe una comprensión empática, la relación del alumno responde al modelo:

Por fin alguien comprende cómo siento y cómo soy yo, sin querer analizarme ni juzgarme. Ahora sí puedo crecer, aprender y tratar de interesarme cada vez más en lo que me enseñan.

La actitud de ponerse en el lugar del otro, de ver el mundo desde el punto de vista del estudiante, es casi inaudita en la escuela tradicional. Sin embargo, ahora es posible entender que gracias a las manifestaciones espontaneas de nuestros alumnos, de sus juegos y bullicios, se nos facilita el conocimiento de su conducta y necesidades. Si aprendemos a tener confianza en la capacidad del alumno para desarrollar sus propias potencialidades, podemos darle la oportunidad de elegir un camino y su propia dirección en el aprendizaje.
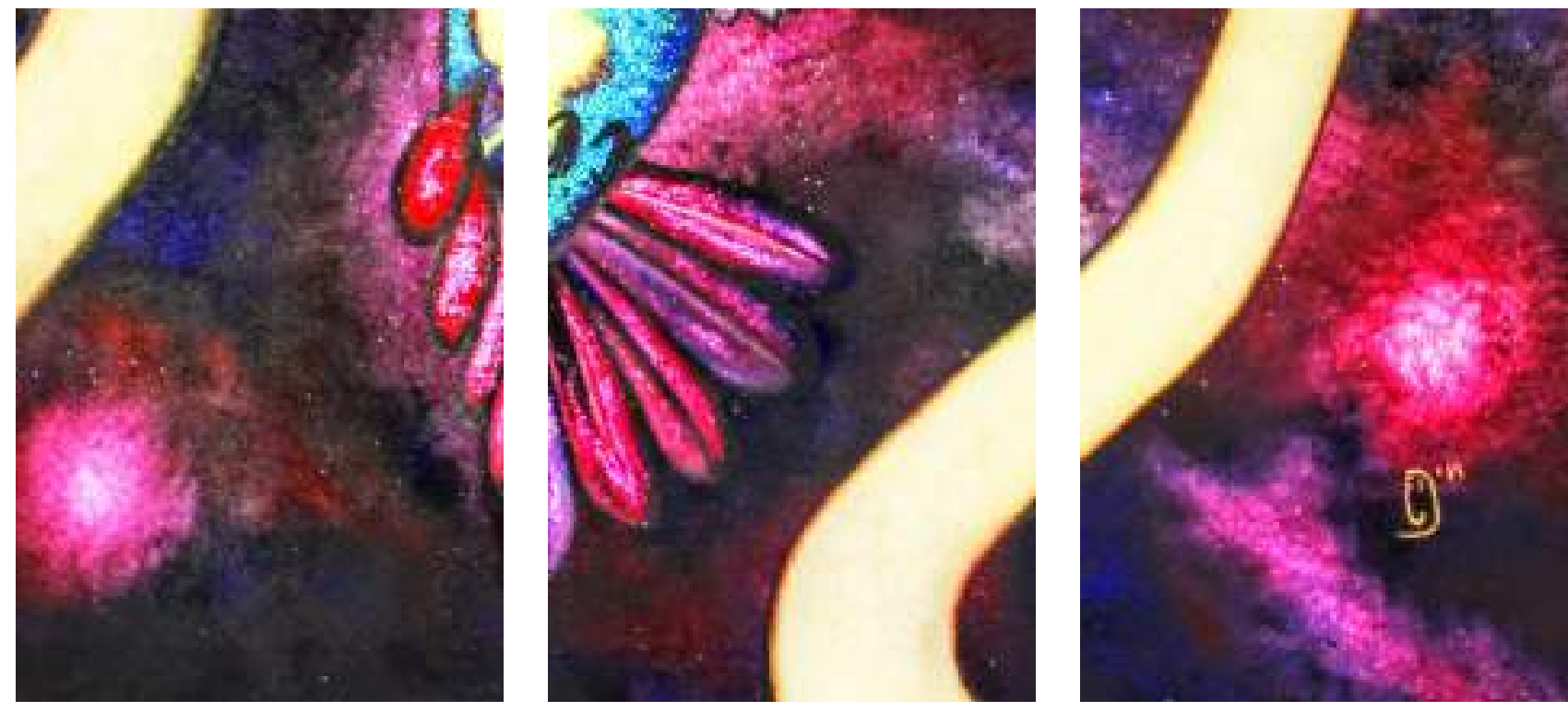
Cuando los estudiantes tienen un contacto real con situaciones importantes para ellos, se interesan por aprender, evolucionar y descubrir; se esfuerzan por mejorar, buscan crear y desarrollan autodisciplina.

El maestro trata de propiciar cierta atmósfera en el aula y un tipo de relaciones personales tales, que impulsen estas tendencias naturales hacia su relación. No obstante, es conveniente tomar en cuenta que los facilitadores de aprendizaje implican ciertos riesgos en apariencia, sobre todo cuando se trata de establecer un nuevo tipo de relación con los alumnos; pero, no por ello, debe decaer el espíritu firme y tesonero del auténtico educador.

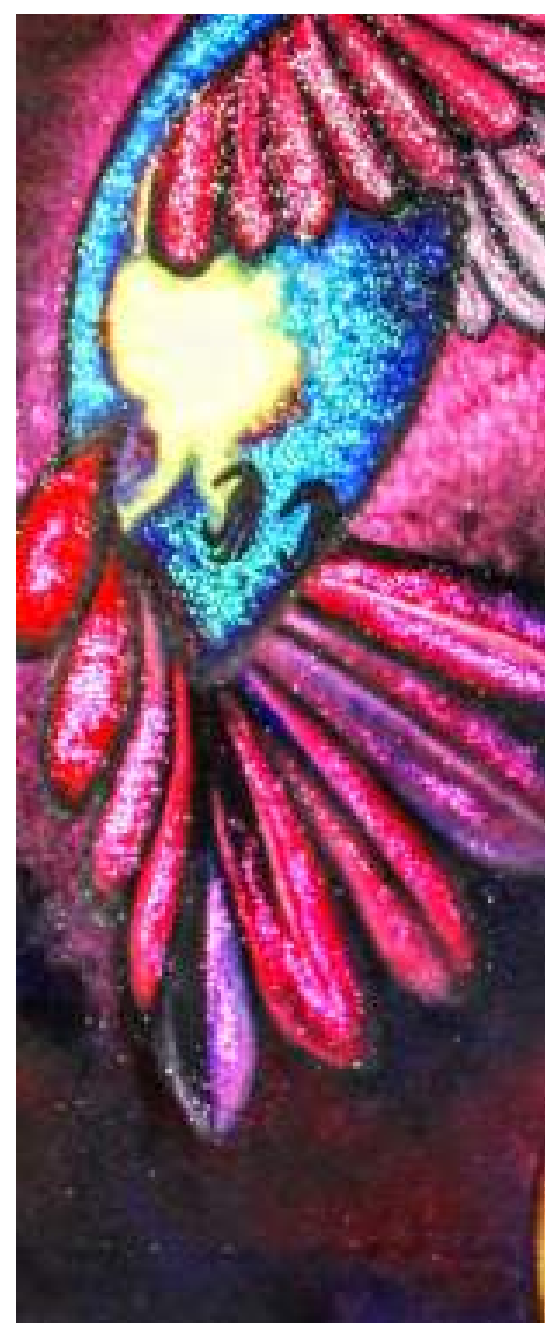

\section{Cuando los estudiantes tienen} un contacto real con situaciones importantes para ellos, se interesan por aprender, evolucionar y descubrir

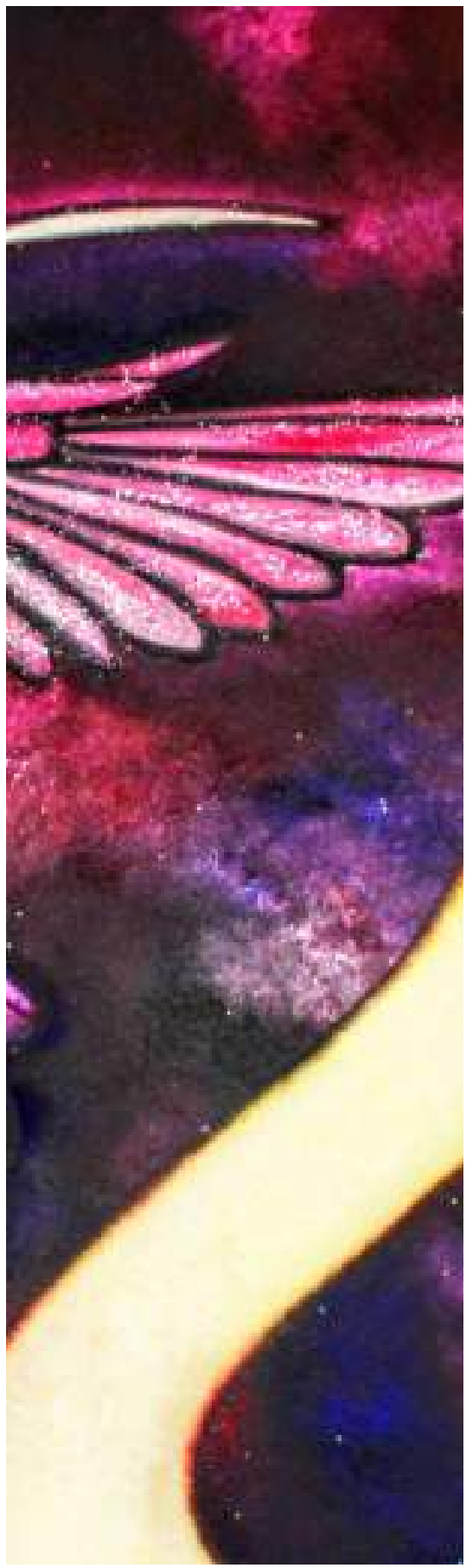

En cuanto al concepto de aprendizaje, cabe mencionar que aunque para muchos continúa siendo fundamentalmente de carácter intelectualista, no debemos olvidar que aun con toda la importancia que tiene este aspecto, representa sólo una parte del aprendizaje total que permanentemente realiza el ser humano.

Entender el aprendizaje como un proceso por el cual la conducta se modifica de manera estable a raíz de las experiencias del sujeto, implica que éste debe vivir lo que aprende y ello exige su participación dinámica en actividades de investigación personal y grupal, tanto dentro como fuera del aula. El papel del docente consiste en incentivar al alumno sobre sus dudas e inquietudes, propiciar la interacción grupal que permita ampliar la visión de los objetivos del aprendizaje, etc, pero no debemos constituirnos en la fuente principal del conocimiento.

Bauler en su libro Ideología, Grupo y Familia dice: Cuando hablamos de aprendizaje grupal aparecen tres elementos como esenciales a definir, pues constituyen su fundamento. Ellos son: información, emoción y producción. Estos elementos giran alrededor de un concepto: el cambio, el cual está implícito en el aprender. 
El aprendizaje grupal pretende lograr que el sujeto participe en su misma formación y que sepa acudir a las fuentes de consulta e información con mayor efectividad posible. Cuando el interés, el discernimiento y la emoción se conjugan con la información, el aprendizaje se convierte en una experiencia dinámica que acarrea nuevas y variadas expectativas.

Con mi experiencia personal como maestro en diferentes niveles y ambientes educacionales, he llegado a la conclusión siguiente:

Cuando algún facilitador de aprendizaje tal como una técnica de dinámica grupal 0 de estudio autodirigido, crea -aunque sea en mínima proporción- un clima de cohesión y co-responsabilidad en el grupo, cuando se confía en las tendencias constructivas del individuo y del grupo, se genera a manera de estímulo-respuesta, un cambio trascendental de interelación entre maestro y alumnos, que proporciona a todos gran-

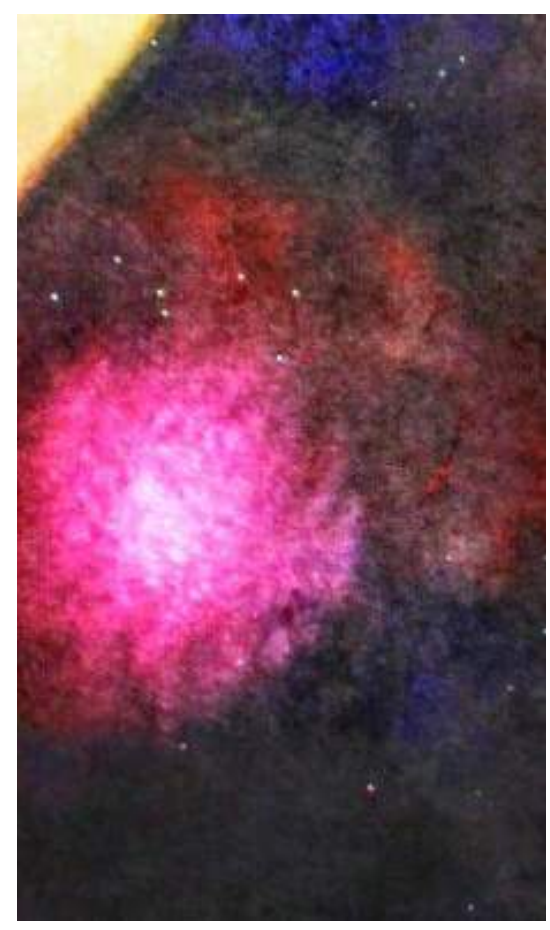

des beneficios de identificación; facilitándose, de tal suerte, la consecución de los objetivos propuestos y, en consecuencia, los resultados se traducen en aprendizajes cualitativamente, con un mayor grado de penetración. Las vivencias positivas, negativas 0 hasta confusas de cuantos participan en el mismo proceso, pasan a formar parte de las experiencias del grupo. El aprendizaje se torna eminentemente vivencial y por ende significativo para el educando y eficaz la tarea del educador.

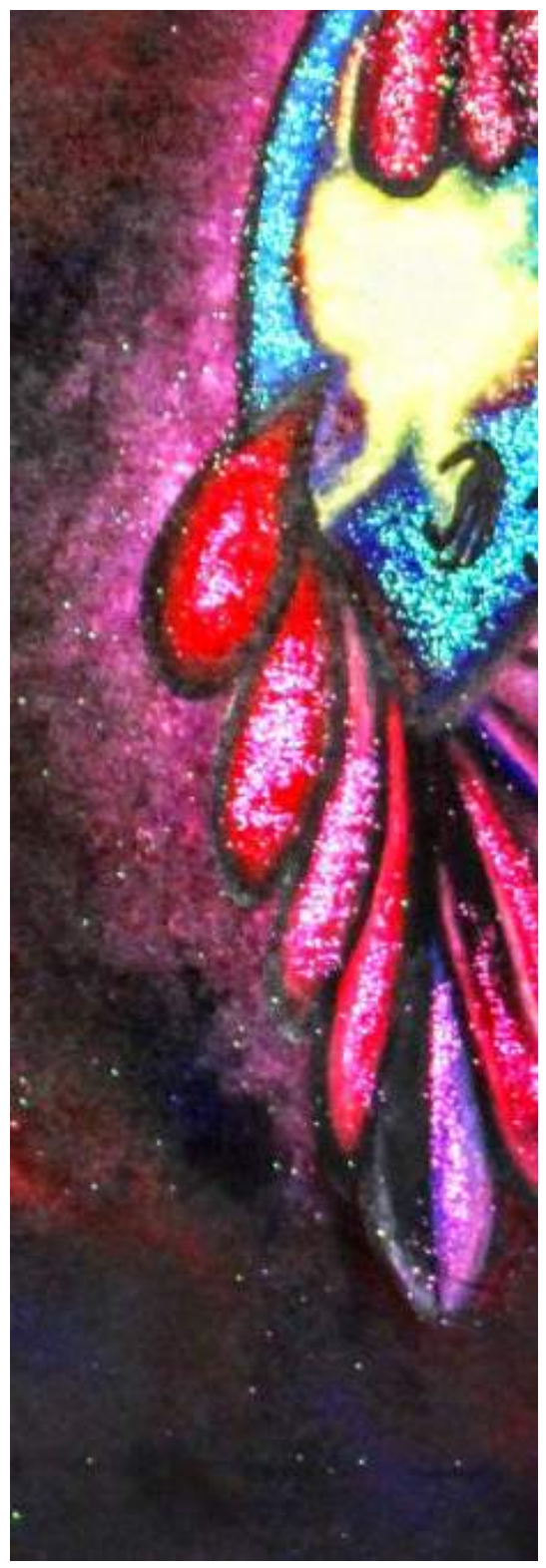

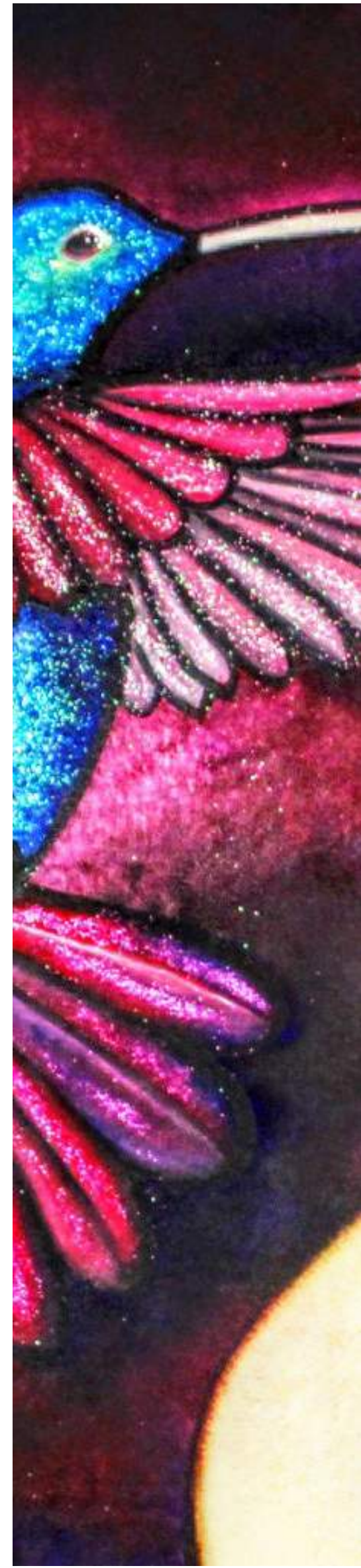

Presencia Universitaria 